\title{
Daniela Blaževska
}

Univerzitet „Sv. Kiril i Metodij“ u Skoplju

Pravni fakultet „Justinijan Prvi“ u Skoplju, Sjeverna Makedonija danielablazevska@gmail.com

d.blazevska@pf.ukim.edu.mk

\section{Televizija i ljudska duša}

\section{Sažetak}

"Kakva je korist čovjeku ako sav svijet zadobije a duši svojoj naudi? Ili kakav će otkup dati čovjek za dušu svoju?"168

Cilj ljudskog života je spasenje duše. Čovjek mora čuvati svoju dušu od štetnih prizora. Cilj ovog rada je istražiti kako televizija kao masovni medij utječe na ljudsku dušu, pri čemu autorica analizira utjecaj televizije na um, želju i volju čovjeka koji je izložen medïskim sadržajima. U radu se izvode zaključci o negativnim efektima televizije na ljudsku dušu te se preporuča selektivna i što kraća izloženost televizijskim programima.

Ključne riječi: televizija, ljudska duša, masovni medij. 


\section{Uvod}

U Svetom pismu su zapisane Isusove riječi: "Kakva je korist čovjeku ako sav svijet zadobije a duši svojoj naudi? Ili kakav će otkup dati čovjek za dušu svoju?"169

Cilj ljudskog života je spasenje duše. Čovjek mora čuvati svoju dušu od štetnih prizora. Masovni mediji napadaju ljudsku dušu sa svih strana. Televizija je audiovizuelni medij, proizvod 20. stoljeća.

Cilj ovog rada je istražiti kako televizija kao masovni medij utječe na dušu čovjeka koji je izložen medijskim sadržajima. Postavljaju se tri istraživačka pitanja na koja trebamo dati odgovore:

1. Što je televizija?

2. Što je ljudska duša?

3. Kakav je utjecaj televizije na ljudsku dušu?

\section{Televizija}

Iz etimološkog ugla, riječ televizija znači: gledati na daljinu. Ova riječ je grčko-latinskog porijekla. "Tele" na grčkom znači: daleko, na daljini ${ }^{170}$. "Visio" na latinskom znači: gledanje (gledati) ${ }^{171}$. Ova riječ potječe od glagola "video" ${ }^{172}$, koji na latinskom znači: gledati, primjećivati ${ }^{173}$.

U Suvremenom leksikonu stranih reči i izraza Ljube Mićunovića televizija se definira kao "predavanje i primanje pokretnih slika iz daljine pomoću električnih metoda za vezu, koje se zasnivaju na rastvaranju slika na veliki broj posebnih svjetlosnih elemenata, „točaka“, odnosno signala, koji se kad dodirnu TV prijemnik pretvaraju u slike"174.

John Fiske ${ }^{175}$ televiziju definira kao "izazivača značenja i zadovoljstva”, kao "kulturnog agenta“, posebno kao „izazivača i cirkulatora značenja”.

Fiske misli da "televizija i njeni programi ne vrše utjecaj na ljude" ${ }^{176}$ te da su "gledaoci i televizija u interakciji”"177. U knjizi “Televizijska kultura” govori o televizijskoj “efektivnosti”"178. On smatra da:

$169 \mathrm{Mt} 16,26, \mathrm{Mk} 8,36-37$.

170 Ljubo Mićunović, Sovremen leksikon na stranski zborovi i izrazi, Naša kniga, Skopje 1990., str. 580.

171 Daniel Chandler i Rod Munday, Media and Communication, Oxford University Press, Oxford and New York 2011., str. 425.

172 video, 2, vidi, visum, gleda, primjećuje, predviđa, brine se

173 Lj. Bosotova i D. Čadikovska, Latinski jazik za III godina kulturološka struka, III izd., Prosvetno delo, Skopje 1999., str. 133.

174 Lj. Mićunović, Sovremen leksikon na stranski zborovi i izrazi, str. 580-581.

175 John Fiske, Television Culture, Methuen, London and NewYork 1987.

176 John Fiske, Television Culture, str. 19.

177 Ibid., str. 19.

178 Ibid., str. 19. 
“Televizija ne 'izaziva' efekte koji se mogu identificirati kod pojedinaca, ali ipak djeluje tako da ideološki promovira i preferira određena značenja svijeta, da cirkulira određena značenja radije nego druga, i da služi jednim društvenim interesima bolje nego drugima”179.

S druge strane, Marie Winn u knjizi "Priključak na drogu" ("The Plug-in Drug")180, sumirala je različita strahovanja koja se odnose na televiziju Glavni zaključak je da televizija može izazvati ovisnost i biti štetna za one koji je gledaju ${ }^{181}$.

Najčešće optužbe su da televizija podstiče eskapizam, pasivnost i ovisnost s jedne strane, a nasilje i delikvenciju s druge ${ }^{182}$. Paul F. Lazarsfeld i Robert K. Merton otkrili su sljedeće disfunkcije masovnih medija: dodjeljivanje i potvrđivanje statusa, potvrđivanje i nametanje društvenih normi i narkotizirajuću disfunkciju ${ }^{183}$.

Dosadašnja istraživanja pokazuju da televizija ima uglavnom negativni efekt na gledaoce. Teorije o televizijskom nasilju nude "silnu podršku vezi gledanje - agresija"184. Američka istraživačica medija Aletta. C. Huston ${ }^{185}$ zaključila je da "akumulirana istraživanja jasno demonstriraju korelaciju između nasilja i agresivnog ponašanja” i da se pritom gledaoci koji provode više vremena ispred televizora ponašaju agresivnije nego oni koji su manje izloženi medijskim sadržajima ${ }^{186}$. Ona sumira obje eksperimentalne i longitudinalne studije koje podržavaju hipotezu da je gledanje nasilja kauzalno povezano sa agresijom. Eksperimenti s djecom preškolskog uzrasta i adolescentima pokazali su prisutnost povišene agresije između gledaoca koji su dobili zadatak da pod određenim uvjetima gledaju nasilnu televizijsku emisiju ili film ${ }^{187}$.

Jedna od najstarijih teorija koja se bavi medijima, teorija katarze, koja tvrdi da gledanje nasilnih sadržaja i agresije na televiziji djeluje „pročišćavajuće“ na negativne osjećaje gledaoca, bila je odbačena od većine znanstvenika. Nakon analize znanstvene evidencije, Scott Andison ${ }^{188}$ je zaključio da televizija stimulira veću agresiju kod pojedinaca. Pokazalo se razumnim prihvatiti teoriju da je televizijsko nasilje stimulans za agresiju a odbaciti teoriju katarze ${ }^{189}$.

Joseph Klapper je godine 1972., u Kongresu SAD rekao da je nesvjestan čvrstih dokaza da gledanje nasilja na televiziji ili na nekom drugom mediju djeluje katarzično ili uzvišeno ${ }^{190}$.

179 Dejvid Mek Kvin, Televizija (medijski priručnik). Clio, Beograd 2000, str. 232.

180 Marie Winn, The Plug-in Drug, Viking Press, Penguin, New York 1977.

181 Marie Winn, The Plug-in Drug.

182 Ibid., str. 232.

183 T. Gruevski, Komunikologija, Studiorum, Skopje 2011., str. 279.

184 Stanley. J. Baran i Dennis K. Davis, Mass Communication Theory (Foundation, Ferment and Future), $4^{\text {th }}$ ed., Thomson Wadsworth, Belmont 2006., str. 193.

185 Aletta. C. Huston, 1992., u: S. J. Baran i D. K. Davis, Mass Communication Theory (Foundation, Ferment and Future). 186 Ibid., str. 193.

187 Ibid., str. 193.

188 Scott Andison, 1977., u Ibid.

189 Ibid., str. 194-195.

190 U. S. Congress, 1972., u Ibid., str. 194. 
Neki autori misle da televizija izaziva loše navike slušanja. Sheila Bentley, američka konzultantkinja za komunikacije, objašnjava da kada čovjek gleda televiziju, sluša na način koji od njega ne zahtijeva da išta zadrži i ne suprotstavlja mu se ako napusti sobu. U prilog ove teze navedene su činjenice da je televizijski program često prekidan reklamama i da ljudi provode i po šest sati dnevno prakticirajući takav način gledanja ${ }^{191}$. Joseph Turow ${ }^{192}$ navodi da su u slučaju televizije studije pokazale da "ljudi ne sjede mirno hipnotizirani svjetlom ekrana, oni se kreću, rade razne stvari i razgovaraju s porodicom i prijateljima" ${ }^{193}$. Istraživači "korištenja i zadovoljenja" masovnih medija smatraju da je publika aktivna, "da pojedinci nisu samo pasivni primatelji poruka"194.

Arhimandrit Rafail Karelin ${ }^{195}$ smatra da televizija:

- uči čovjeka misliti u čulnim predstavama, izaziva raspršenost i laku prijemčivost za utiske, otupljuje racionalno pamćenje i slabi stvaralačke snage čovjeka

- unificira, izjednačava, pojednostavljuje i obezličuje ljude

- hipnotizira

- širi nervne i psihičke bolesti

- uči ljude da budu okrutni

- međusobno otuđuje ljude koji žive u istom domu i porodici, zamijenivši druženje i zajedničarenje ljudi varkama i priviđenjima ekrana

- ubija srce relegije - molitvu ${ }^{196}$

U svom kritičkom osvrtu o televiziji arhimandrit Rafail Karelin objašnjava da je televizija stvorila novu vrstu čovjeka kojeg naziva homo medium, „čovjeka sa živčanim sistemom istrošenim od neprekidnog gledanja kao od stalnog pijanstva, čovjeka u duševnom rasulu koji ne može odrediti granicu i postaviti filter vanjskoj informaciji i usvaja je, tako reći, u sirovom obliku - nekritički, samo prostim mehaničkim pamćenjem"197.

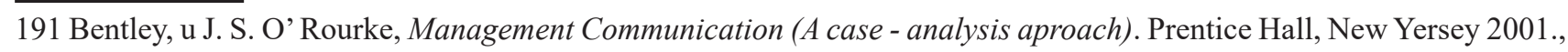
str. 119.

192 Joseph Turow, Mediji danas, Uvod u masovne komunikacije. Clio, Beograd 2012.

193 Joseph Turow, Mediji danas, Uvod u masovne komunikacije, str. 2.

194 Ibid., str. 243.

195 Arhimandrit Rafail Karelin, Put spasenja u XXI veku, Biblioteka Očev dom pri Verskom dobrotvornom starateljstvu Arhiepiskopije beogradsko - karlovačke, Beograd 2011.

196 Arhimandrit Rafail Karelin, Put spasenja u XXI veku.

197 Ibid., str. 195-197. 


\section{Ljudska duša}

Čovjek je sastavljen od tijela, duše i duha. Bog je stvorio dušu ${ }^{198}$. Duh je "oko duše"199. O postojanju ljudske duše svjedoče Sveto pismo i Sveti oci.

Prvi čovjek Adam je duša živa. U Knjizi Postanka Svetog pisma zapisano je: “A stvori Gospod Bog čoveka od praha zemaljskoga, i dunu mu u nos duh životni; i posta čovek duša živa“" ${ }^{200}$.

Sveti Isak Sirijski ${ }^{201}$ tumači da se u Svetom pismu "ne pravi strogo razlikovanje između onoga što je svojstveno duši i onoga što je svojstveno telu" ${ }^{202}$.

Ako dušu razmatramo iz kuta borbe protiv strasti, Sveti oci svjedoče da duša ima tri sile: um, želju i volju ${ }^{203}$ ) ili misleni, željni i afektivni dio ${ }^{204}$.

Sveti Ignjatije Brjančaninov ${ }^{205}$ navodi da "Shimonah Vasilije, pozivajući se na Svetog Teofilakta i druge oce, tvrdi da su tri sile duše - slovesna sila, sila revnosti i sila želje, u srcu raspoređene ovako: u prsima i u gornjem dijelu srca prisutna je slovesna sila; u sredini - sila revnosti; a u donjem dijelu - sila želje, ili prirodna požuda“.

Sveti Makarije Veliki otkriva da duša kao i anđeli ima svoj lik i izgled, a to je "lik i izgled spoljašnjeg čoveka u njegovom telu” ${ }^{206}$. Duše su "fina, eterična tela", "na oči, uši, ruke i noge duše odeveni su odgovarajući udovi tela” ${ }^{207}$.

Ljudska duša je uglavnom nevidljiva za ljudsko oko. Sveti Makarije Veliki otkriva da "najsavršeniji hrišćani, očišćeni i prosvećeni Duhom Svetim, vide lik duše, ali takvo savršenstvo i viđenje dostižu samo retki među svetima" ${ }^{208}$.

198 Mitropolit Jerotej Vlahos, Obolelost i lečenje duše u pravoslavnom predanju, u: J. Srbulj (ured.), Lečenje duše u Pravoslavnoj Crkvi, Biblioteka Očev dom pri Verskom dobrotvornom starateljstvu Arhiepiskopije beogradsko-karlovačke, Beograd, 2010., str. 8, str. 5-73.

199 Arhimandrit Rafail Karelin, Tajnata na spasenieto, Manastir „Sveti Atanasij Veliki”, Žurče - Demir Hisar 2008., str. 50.

2001 Moj, 7.

201 Sveti Isak Sirijski, Podvižnička slova, 3. izd., Pravoslavna misionarska škola pri hramu Svetog Aleksandra Nevskog, Beograd 2016.

202 Sveti Isak Sirijski, Podvižnička slova, str. 25.

203 Arhimandrit Rafail Karelin, Tajnata na spasenieto, Manastir „Sveti Atanasij Veliki”, Žurče - Demir Hisar 2008., str.28.

204 Mitropolit Jerotej Vlahos, Obolelost i lečenje duše u pravoslavnom predanju, u: J. Srbulj (ured.), Lečenje duše u Pravoslavnoj Crkvi, Biblioteka Očev dom pri Verskom dobrotvornom starateljstvu Arhiepiskopije beogradsko - karlovačke, Beograd 2010., str. 9.

205 Sveti Ignjatije Brjančaninov, Enciklopedija pravoslavnog duhovnog života, 2. izd., Pravoslavna misionarska škola pri hramu Svetog Aleksandra Nevskog, Beograd 2008., str. 287.

206 Ibid., str. 120.

207 Ibid.

208 Ibid. 
Sveti Isak Sirijski ${ }^{209}$ objašnjava da prirodno stanje duše jest "viđenje božanskih tvari, čulnih i mislenih" ${ }^{110}$. Natprirodno stanje jest "podsticaj ka sozercanju ${ }^{211}$ nadsuštnoga Božanstva”, a protuprirodno stanje“ kretanje duše onih [ljudi] koji su pometeni strastima” ${ }^{212}$. Duša je po prirodi smrtna, a po blagodati besmrtna ${ }^{213}$. Ljudska duša umire kada ne živi po Bogu i u sebi nema energiju Duha Svetoga ${ }^{214}$.

\section{Utjecaj televizije na ljudsku dušu}

“Čovek je slovesno biće i misli posredstvom reči. Televizija koristi zvuk i sliku i uči čoveka da misli u slikama“215.

Za ljudsku dušu posebno su štetne televizijske serije, filmovi, crtani filmovi, reklame, koji stvaraju nerealan televizijski svijet, u kojeg uvlače čovjeka koji na taj način bježi iz realnog svijeta i gubi svoje dragoceno vrijeme. Umjesto da se posveti dušokorisnim, duhovnokorisnim i bogougodnim poslovima, čovjek provodi vrijeme ispred televizora kao opčinjen. Vrijeme ne prolazi, već je nepovratno izgubljeno i šteta koja je duši nanesena ne može se izmjeriti. Pritom postoje dva brojenja vremena: vanjsko ili kalendarsko, i unutrašnje vrijeme svakog čovjeka koje mogu trošiti te njegove strasti $^{216}$. Sinhronizacije televizijskih serija i ljudski glasovi crtanih likova kreiraju dvostruko lažni svijet.

Medijska stvarnost ne postoji zato što je TV aparat jedina stvar koju čovjek može dodirnuti, jedina materija s kojom može ostvariti taktilnu komunikaciju. Također, ova "stvarnost” ne može se nazvati stvarnošću zato što nije realna već irealna, nije istinita već lažna, ali ona jest stvarnost za ljude koji učestvuju u stvaranju medijskih sadržaja i njihovim dušama nanosi veću štetu. Konzument medijskih sadržaja sam stvara stvarnost od onoga što je posredovano medijima. Za njega je stvarnost to što sjedi ispred televizora i ono što gleda, čuje, opaža. On konstruira svoju stvarnost od bezbroj slika i utisaka koji se urezuju u njegovu dušu i ne može ih se lako osloboditi čak i kad bi htio.

Televizor je domove pretvorio u kazališta, kina, kavane. Čovjekova potreba za informiranjem ugušila se u poplavi lažnih i štetnih medijskih sadržaja. Informativna i obrazovna funkcija televizije je svedena na minimum. Čovjek koji provodi više vremena ispred televizora gleda i ono što ne bi htio vidjeti, sluša i ono što ne bi htio čuti. Televizija potiče fantaziju kojoj možemo pristupiti kritički. Sveti oci uče da je fantazija (uobrazilja) „prirodna energija ili moć duše” i „da se aktivirala u čoveku

209 Sveti Isak Sirijski, Podvižnička slova.

210 Ibid., str. 24.

211 sozercanje, od korijena riječi „zrenje“, sagledati, kontemplacija.

212 Ibid., str. 24.

213 Mitropolit Jerotej Vlahos, Obolelost i lečenje duše u pravoslavnom predanju, str. 18.

214 Ibid.

215 Arhimandrit Rafail Karelin, Put spasenja u XXI veku, Biblioteka Očev dom pri Verskom dobrotvornom starateljstvu Arhiepiskopije beogradsko - karlovačke., Beograd 2011., str. 195.

216 Blaženi Augustin, u Arhimandrit Rafail Karelin, Tajnata na spasenieto, Manastir „Sveti Atanasij Veliki”, Žurče - Demir Hisar 2008., str. 68. 
posle Grehopada i njome su počele da gospodare lažne slike i ideje, što je potom počelo da stvara ozbiljne probleme ljudskoj duši” ${ }^{217}$. Mitroplolit Jerotej Vlahos ${ }^{218}$ fantaziju uspoređuje s televizorom „koji može da emituje televizijsku sliku, ali ne može sam da stvara sliku”"19. Izloženi audiovizuelnim sadržajima, gledaoci mogu misli i pomisli, osjećaje, potrebe, želje koje pripadaju nekom drugom prihvatiti kao svoje. Čak i gledaoci koji imaju određeno teoretsko znanje o funkcioniranju masovnih medija ne mogu izbjeći negativne efekte audiovizuelnih sadržaja koje gledaju. Televizijski sadržaji mogu kod gledaoca izazvati zaista loše pomisli. Misli su „razumski predlozi”, dok su pomisli „razumski predlozi koji su smešani sa odgovarajućim slikama (predstavama) i podsticajima što u um dolaze kroz gledanje i slušanje, ili i kroz jedno i kroz drugo”220. Pomisli su „slike i podsticaji, koje utelovljuju određene poruke". ${ }^{221}$ Čovek se mora boriti protiv loših misli i njegovati dobre. Od izvanredne važnosti je da čovek čuva svoj um, zato što ako prihvati samo jednu lošu misao, može svojoj duši izazvati enormnu štetu. Odmah čim uključi televizor čovjek je izložen određenim sadržajima čak i kad to ne želi. Na primjer, dok gleda neku obrazovnu ili dječju emisiju izložen je porukama reklamnog bloka ili dok mijenja kanale može vidjeti i čuti štetne prizore.

Možemo da zaključiti da televizija vrši negativan utjecaj na tri sile ljudske duše na sljedeći način:

1. Na razumski dio duše televizija utječe tako što smanjuje intelektualnu moć, iscrpljuje nervni sistem, pomračuje moć rasuđivanja.

2. Na želje televizija utječe tako što povećava nerazumne želje i potrebe izazivajući različita iskušenja kod gledatelja.

3. Na volju utječe tako što ju slabi izazivajući apatiju i hipnozu, a na afektivni dio duše televizija utječe tako da izaziva ljutnju, zlobu, bijes, agresiju, podstiče nasilje.

Pritom na sve tri sile duše utječe istovremeno. Kao što je zapisao arhimandrit Rafail Karelin, pod utjecajem televizijskih sadržaja duša postaje «razmaženo mlitava, čulna i histerična” ${ }^{222}$.

Ljudska manifestacija dužeg utjecaja televizije može biti različita u različitim vremenima, u ovisnosti od strasti koja dominira čovjekom u tom vremenu i tipu medijskih sadržaja kojima je izložen.

Religiozni ljudi gledaju na televiziju kao na «neprijatelja ${ }^{223}$ i zlo" ${ }^{224}$. Sveti Nil Sinajski je rekao da "svako tko gleda na zlo bez gađenja, uskoro će početi da gleda sa zadovoljstvom”225.

217 Mitropolit Jerotej Vlahos, Obolelost i lečenje duše u pravoslavnom predanju, str. 18.

218 Ibid.

219 Ibid., str. 18.

220 Ibid., str. 58.

221 Ibid., str. 58-59.

222 Arhimandrit Rafail Karelin, Put spasenja u XXI veku, str. 195.

223 Arhimandrit Rafail Karelin, Put spasenja u XXI veku, str. 198.

224 Starac Pajsije, Čuvajte dušu (Razgovori sa starcem Pajsijem Svetogorcem o spasenju u savremenom svetu), 4. izd., Biblioteka Obraz svetački, Pravoslavna misionarska škola pri Hramu Svetog Aleksandra Nevskog, Beograd 2011., str. 36-37.

225 Goran Veljković, Pravoslavni podsetnik za prostu 2014., Duhovni lug, Kragujevac 2014., str. 62. 
Televizija je hipnotizer i veoma sugestivna, tako da ono što na početku izgleda odbojno i uznemiravajuće, kasnije može postati privlačno ako gledalac nastavi primati te poruke. Zato štetne slike i zvukove treba izbjegavati, jer ako čovjek s njima započne konverzaciju, duša ne može ostati neoštećena. Čak i nešto što izgleda dobro ima negativan utjecaj na ljudsku dušu a da recipienti i ne moraju toga biti svjesni. Televizija krije opasnosti i za medijske djeatnike koji se bave novinarskim poslom. Stalno u trci s događajima, pod stresom obavljanja zadatka prije krajnjeg roka, u stalnoj žurbi da pripreme prilog ili emisuju za uho i oko gledaoca, novinari sami sebi postaju neprijateljima.

Ljudskoj duši je više potrebna molitva, a manje televizija. Više joj je potrebno gledanje u visinu nego na daljinu. Više joj je potrebno gledanje u sebe nego izvan sebe.

\section{Zaključak}

Televizija ima negativan uticaj na tri sile ljudske duše: um, želju i volju. Ona hipnotizira, smanjuje intelektualnu moć, izaziva iskušenja, ohrabruje želje, stvara potrebe, slabi volju i izaziva apatiju.

Čak i ono što ponekad ljudima izgleda dobro (na primjer crtani filmovi koji razvijaju imaginaciju), ima negativan efekt na ljudsku dušu, čega recipienti ne moraju biti svjesni. Isto tako, ono što na početku izgleda odbojno i uznemiravajuće za gledaoce, kasnije može postati privlačno ako nastave primati isti medijski sadržaj. Čak i gledaoci koji imaju teorijsko znanje o funkcioniranju televizije kao masovnog medija ne mogu izbjeći negativni efekt audiovizuelnih sadržaja koje gledaju. Televizija putem svojih sadržaja zaista može izazvati loše pomisli kod gledatelja. Čovjek se mora boriti protiv loših pomisli i njegovati dobre misli. Izuzetno je važno za čovjeka da ogradi svoj um, jer ako prihvati samo jednu lošu pomisao, može izazvati veliku štetu svojoj duši. Zato ako želi sačuvati svoju dušu, preporuka je - što kraća i selektivna izloženost televizijskim sadržajima.

\section{Literatura:}

Архимандрит Рафаил Карелин, Пут спасењау XXI веку, Библиотека Очев дом при Верском добротворном старатељству Архиепископије београдско - карловачке, Београд 2011.

Arhimandrit Rafail Karelin, Put spasenja u XXI veku, Biblioteka Očev dom pri Verskom dobrotvornom starateljstvu Arhiepiskopije beogradsko - karlovačke., Beograd 2011.

Архимандрит Рафаил Карелин, Тајната на спасението, Манастир „Свети Атанасиј Велики”, Журче - Демир Хисар 2008.

Arhimandrit Rafail Karelin, Tajnata na spasenieto, Manastir „,Sveti Atanasij Veliki”, Žurče - Demir Hisar 2008.

Baran, Stanley. J., i Davis, Dennis. K., Mass Communication Theory (Foundation, Ferment and Future), $4^{\text {th }}$ ed., Thomson Wadsworth, Belmont 2006. 
Босотова Љ и Чадиковска, Д., Латински јазик за III година културолошка струка, III изд., Просветно дело, Скопје 1990.

Bosotova LJ. i Čadikovska D., Latinski jazik za III godina kulturološka struka, III izd., Prosvetno delo, Skopje 1990.

Chandler, Daniel. i Munday, Rod., Media and Communication, Oxford University Press, Oxford and New York 2011.

Fiske, John,. Television Culture, Methuen, London and NewYork 1987.

Груевски, Тоте, Комуникологија, Студиорум, Скопје 2011.

Gruevski, Tome, Komunikologïa, Studiorum, Skopje 2011.

Mek Kvin, Dejvid, B., Televizija (medijski priručnik), Clio, Beograd 2000.

Митрополит Јеротеј Влахос, Оболелост и лечење душе у православном предању, у: Ј. Србуљ (уред.), Лечење душе у Православној Цркви, Библиотека Очев дом при Верском добротворном старатељству Архиепископије београдско - карловачке, Београд 2010., стр. 5-73.

Mitropolit Jerotej Vlahos, Obolelost i lečenje duše u pravoslavnom predanju, u: J. Srbulj (ured.), Lečenje duše u Pravoslavnoj Crkvi, Biblioteka Očev dom pri Verskom dobrotvornom starateljstvu Arhiepiskopije beogradsko - karlovačke, Beograd 2010., str. 5-73.

Миќуновиќ, Љубо, Современ лексикон на странски зборови и изрази, Наша книга, Скопје 1990.

Mićunović, Ljubo, Sovremen leksikon na stranski zborovi i izrazi, Naša kniga, Skopje 1990.

O’ Rourke, James, S., Management Communication (A case- analysis aproach), Prentice Hall, New Yersey, 2001.

Свети Игњатије Брјанчанинов, Енциклопедија православног духовног живота, 2. изд., Православна мисионарска школа при храму Светог Александра Невског, Београд 2008.

Sveti Ignjatije Brjančaninov, Enciklopedija pravoslavnog duhovnog života, 2. izd., Pravoslavna misionarska škola pri hramu Svetog Aleksandra Nevskog, Beograd 2008.

Свети Исак Сиријски, Подвижничка слова, 3. изд., Православна мисионарска школа при храму Светог Александра Невског, Београд 2016.

Sveti Isak Sirijski, Podvižnička slova, 3. izd., Pravoslavna misionarska škola pri hramu Svetog Aleksandra Nevskog, Beograd 2016.

Светосавац, Старије генерације су одговорне за пороке младих, Парохијски лист Храма Светог Саве у Београду, 63, (VII-VIII/2014.), Храм Светог Саве, Београд: 
Svetosavac, Starije generacije su odgovorne za poroke mladih, .Parohijski list Hrama Svetog Save u Beogradu, 63, (VII-VIII/2014.), Hram Svetog Save, Beograd

Старац Пајсије. Чувајте душу (Разговори са старцем Пајсијем Светогорцем о спасењу у савременом свету), 4. изд., Библиотека Образ светачки, Православна мисионарска школа при Храму Светог Александра Невског, Београд 2011.

Starac Pajsije, Čuvajte dušu (Razgovori sa starcem Pajsijem Svetogorcem o spasenju u savremenom svetu), 4. izd., Biblioteka Obraz svetački, Pravoslavna misionarska škola pri Hramu Svetog Aleksandra Nevskog, Beograd 2011.

Tjurou, Džozef., Medīi danas, Uvod u masovne komunikacije, Clio, Beograd 2012.

Вељковић, Горан, Православни подсетник за просту 2014., Духовни луг. Крагујевац 2014.

Veljković, Goran, Pravoslavni podsetnik za prostu 2014., Duhovni lug, Kragujevac 2014.

Winn, Marie, The Plug-in Drug, Viking Press, Penguin, New York 1977.

\title{
Television and Human Soul
}

\begin{abstract}
"What is the benefit of the human if he obtains the whole world and damage the soul? Or what kind of ransom will give the man for his soul?" (Mt 16, 26, $M k$ 8, 36-37).

The goal of the human life is the salvation of the soul. The human must save his soul from the harmful sights. The aim of this paper is to research how the television as mass media influence on the human soul. Thus, the author analyzes the influence of television on the mind, wish and will of the human that is exposed to media contents. In the paper are offered conclusions about the negative effects of television on human souls and it is recommended selective and as short as possible exposure to television programs.
\end{abstract}

Key words: television, human soul, mass media.

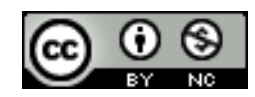

This journal is open access and this work is licensed under a Creative Commons Attribution-NonCommercial 4.0 International License. 